\title{
Prescriptions Pattern Available at Rural Household
}

\author{
Md. Mahfuzar Rahman \\ Prof. Dr. Md. Mahfuzar Rahman Professor \& Head, Department of Community Medicine \\ Anwer Khan Modern Medical College, Dhanmondi, Dhaka
}

\begin{abstract}
This was a descriptive type of cross-sectional study conducted in three villages of Shahjadpur Upazila in the month of October, 2010 among the rural households who visited medical practioners for the last three months. It was aimed to determine the socio-demographic characteristics of the respondents, availability of prescriptions, diagnosis written, number of drugs and antibiotics including its duration written within the prescription. It also determines the duration of antibiotic, dose and course including the advices on life style mentioned in the prescription in particular.

It was revealed from the findings that $73.27 \%$ respondents were within $15-44$ years of age with mean age 34.8 years and $\mathrm{SD} \pm 13.09$. In this study $68 \%$ respondents were attended doctors chamber during last three months, of them prescriptions were available to $57 \%$ respondents for investigation according to the stated objectives. Number of drugs in one prescription was 3-5 in 77\% prescriptions. On the other hand 58\% prescriptions were having 1-2 antibiotics. However, dose of antibiotics were not mentioned to about $31 \%$ prescriptions only. The duration 3-6 days of antibiotics was mentioned only about $23 \%$ prescriptions. Advices on life style and diagnosis were mentioned only to 32 and $52 \%$ prescriptions respectively. The investigation also revealed the qualification of prescribers and found $22.64 \%$ prescriptions by non-qualified doctors.

The finding of the study can be a basis to take appropriate measures among prescribers in the locality towards maintaining the standard and rationality of prescriptions for the patients seeking drug treatment for any type of ailments. It will also help practitioners to provide a rational prescription to the consumers in regards to the number of drugs as well as clarity of instruction of its uses in deed.
\end{abstract}

Key Words: Prescription, Pattern, Rural Household

\section{Introduction}

In most instances drugs does no apparent harm to the patient but sometimes the results are tragic. Even when the patient is not in injured; overuse of medicine is an undesirable behavioral pattern ${ }^{1}$. In order to facilitate the use of drugs, WHO in 1975 discussed about drug policy which was followed by the selection of 250 drugs $^{2}$. Subsequently, joint collaboration of WHO and UNICEF resulted in the historic Alma-Ata declaration emphasizing primary health care ${ }^{3}$.

Irrational drug use and inappropriate prescribing by professionals is a world wide phenomenon, It is very prevalent in developing countries due to lack of continuous education, training and up-todate knowledge of clinical pharmacology, information from promotional materials of pharmaceutical companies, patient's pressure for medications of their choice, uncertainty about diagnosis ${ }^{4}$ and direct stake of prescribers in selling more drugs ${ }^{5}$. Most diseases are in fact self limiting through the body's own defense mechanism ${ }^{6}$. WHO stresses that drugs are essential tools for health care and for the improvement of quality of life ${ }^{6}$. Bangladesh's national drug policy was promulgated in June, $1982^{7}$ initially, the pharmaceutical industry reacted adversely.

In Sri Lanka, Angunawela (1988) noted that on an average, 3-5 drugs were prescribed pre visit 15 
while 7.2 drugs were prescribed in private institutions ${ }^{8}$. Empirical results of studies carried out in Japan (1985) show that physicians tend to increase their income by prescribing more drugs than are needed for any particular disease ${ }^{9}$.

Angunawela (1989) pointed out that drugs are sometimes prescribed without any indication for their use. These drugs are mostly mixtures, vitamins, and antimicrobials. The addition of such drugs in prescriptions tends to increase the number of drugs prescribed per encounter and consequently leads to polypharmacy ${ }^{10}$.

The motivational force working behind irrational prescribing was stated by physicians in USA as patient's demand $(46 \%)$, intsentional use as placebo effect (24\%) and own clinical experience $^{11}$. In many developing countries, including Bangladesh, medicines are available free of charge through health services. Drug prescribing has been an age old practice among people who tend to alleviate human physical sufferings. They include trained modern day physicians, self taught people and people trained in traditional medicine. It was considered that polypharmacy, its extent and the reasons behind it, should be identified into greater depths, in our social context. The provider brings a mixture of clinical, commercial, and social motives derived from past experience. The ensuing negotiations in this context produce a pattern of prescribing, whether it is over-prescribing, polypharmacy, incorrect of harmful drugs of correct costeffective theapeutics ${ }^{12}$.

In USA, a study carried out among the medical officers showed that though they used various forms of literatures and written materials as source of drug information, they maintained that the most influential source was colleagues ${ }^{13}$.

Another study involving several industrialized countries of the world (1989), showed that more than $90 \%$ of the physicians see detailers and a substantial number of them rely on these detailers as an important source of information concerning drugs. This study further showed that detailers are highly successful in altering physicians, prescribing habits ${ }^{14}$.
Plumridge (1983) identified several factors and sources of drug information that he considered were responsible for influencing physicians' prescribing pattern. Among them were pharmaceutical companies and their representatives, house journals, drug samples, reference books, meeting, colleagues and social cost and reward ${ }^{15,16}$.

Doctors bear the main responsibility for the use of drug. Several countries have adopted essential drugs list but only a few have had any active support from the established doctors. In general, they are disinclined to change their attitude and prescribing behaviour ${ }^{17}$.

A study in Denmark found that $61.7 \%$ of the prescriptions were incorrect. The error most noticeable was the limiting of issues and indications of reasons (diagnosis) for use in $32.4 \%$ of the prescriptions ${ }^{18}$.

Analysis of the prescriptions written for patients attending out patient department of health institutes in Sri Lanka showed that of all the prescriptions $80.4 \%$ were appropriate (rational) and $98.6 \%$ were prescribed in correct dosage ${ }^{19}$.

A great number of unnecessary drugs in the market are destroying rather than helping public health and bring ill effect to the populations. Moreover, the aggressive promotion of drugs by multinational and national companies is playing a great role to over use and irrational use of drugs among the population. World Health Organization (WHO) suggested and identified a number of essential drugs for the developing countries that proves significant efficiencies in promoting basic health care in the developing countries.

The findings of the study will help practitioners to provide a rational prescription to the consumers in regards to the number of drugs as well as clarity of instruction of its uses in deed.

\section{Objectives}

i. To determine the socio demographic characteristics of respondents.

ii. To find out the prescriptions available among the respondents in different sexes.

iii. To list the diagnosis of diseases in the prescriptions. 
iv. To find out the number of drugs written in one prescription.

v. To identify the number of antibiotics written in a prescription.

vi. To determine the duration of antibiotic per encounter

vii. To identify the dose, course of drug and the advices on life style in prescriptions.

\section{Methodology}

It was a descriptive cross sectional study in villages Saktipur, Parkola and Prannathpur of Shahjadpur Upazila in the month of October, 2010 among rural households who visited the medical practitioner for the last 03 (Three months) and willing to respond. The sampling technique was purposive and convenient in nature. The size of the sample was 550 (Five hundred fifty) rural households. The data were collected face to face through house visit by an interview schedule (Questionnaire) duly pre-tested. It was processed and analyzed manually and by computer using appropriate software.

\section{Results}

Table I: Distribution of respondents by age $n=550$

\begin{tabular}{ccc}
\hline Age in years & Number of respondents & Percentage \\
\hline $15-24$ & 155 & 28.18 \\
$25-34$ & 141 & 25.64 \\
$35-44$ & 107 & 19.45 \\
$45-54$ & 97 & 17.63 \\
$55-64$ & 50 & 09.10 \\
Total & $\mathbf{5 5 0}$ & $\mathbf{1 0 0 . 0 0}$ \\
\hline
\end{tabular}

Almost $73.27 \%$ respondents were found within age of 15-44 years of age

Mean: 34.8 years, SD: \pm 13.09

\section{Graph-1 (Line)}

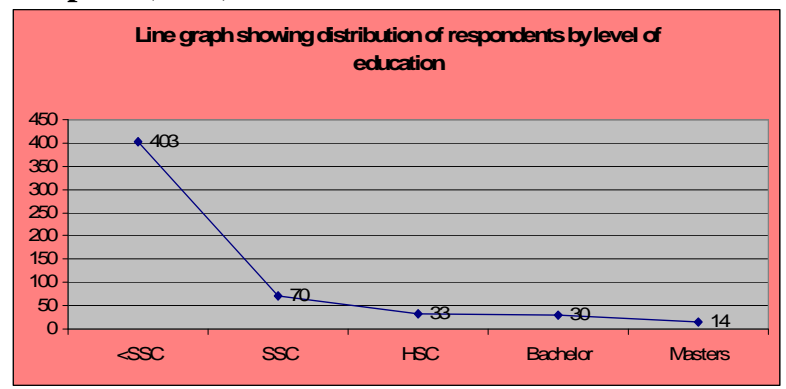

Almost $73 \%$ respondents were found below SSC level of education
Table II: Distribution of respondents by having prescription for last three months $\mathrm{n}=550$

\begin{tabular}{ccc}
\hline $\begin{array}{c}\text { Having } \\
\text { prescription }\end{array}$ & $\begin{array}{c}\text { Number of } \\
\text { respondents }\end{array}$ & Percentage \\
\hline Yes & 318 & 57.82 \\
No & 232 & 42.18 \\
Total & $\mathbf{5 5 0}$ & $\mathbf{1 0 0 . 0 0}$ \\
\hline
\end{tabular}

However, availability of prescriptions was found only to $57 \%$ respondents. About $11 \%$ prescriptions were found lost by the respondents

Table III: Distribution of respondents by number of drugs in one prescription $\mathrm{n}=318$

\begin{tabular}{ccc}
\hline $\begin{array}{c}\text { Number of } \\
\text { drugs }\end{array}$ & $\begin{array}{c}\text { Number of } \\
\text { respondents }\end{array}$ & Percentage \\
\hline 1 & 6 & 1.89 \\
2 & 36 & 11.32 \\
3 & 86 & 27.04 \\
4 & 110 & 34.59 \\
5 & 51 & 16.04 \\
6 & 21 & 6.60 \\
7 & 8 & 2.52 \\
Total & $\mathbf{3 1 8}$ & $\mathbf{1 0 0 . 0 0}$ \\
\hline
\end{tabular}

Only 3-5 drugs in one prescription were written to about $77 \%$ prescriptions

Graph-2 (Pie)

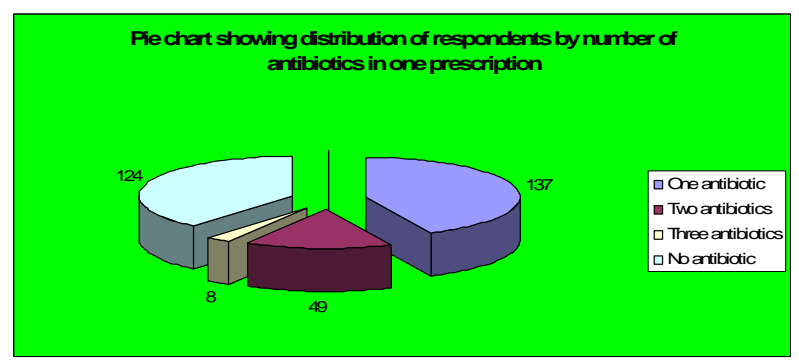

About 58\% prescriptions were found having 1-2 antibiotics

Table IV: Distribution of respondents by duration antibiotics in days $n=138$

\begin{tabular}{ccc}
\hline $\begin{array}{l}\text { Duration of } \\
\text { antibiotics in days }\end{array}$ & $\begin{array}{l}\text { Number of } \\
\text { respondents }\end{array}$ & Percentage \\
\hline 1 & 64 & 46.38 \\
2 & 42 & 30.43 \\
3 & 15 & 10.87 \\
4 & 3 & 2.17 \\
5 & 6 & 4.35 \\
6 & 8 & 5.80 \\
Total & $\mathbf{1 3 8}$ & $\mathbf{1 0 0 . 0 0}$ \\
\hline
\end{tabular}

Only about 23\% prescriptions were having 3-6 days of duration of antibiotics 
Prescriptions pattern available at rural household

Table V: Distribution of respondents by advice on life style in the prescription $\mathrm{n}=318$

\begin{tabular}{ccc}
\hline $\begin{array}{l}\text { Advices mentioned } \\
\text { on life style }\end{array}$ & $\begin{array}{l}\text { Number of } \\
\text { respondents }\end{array}$ & Percentage \\
\hline Yes & 102 & 32.08 \\
No & 216 & 67.92 \\
Total & $\mathbf{3 1 8}$ & $\mathbf{1 0 0 . 0 0}$ \\
\hline
\end{tabular}

Advices on life style were found only to $32 \%$ prescriptions

Table VI : Distribution of respondents by diagnosis of disease mentioned in the prescription $n=318$

\begin{tabular}{lcc}
\hline $\begin{array}{l}\text { Diagnosis of disease } \\
\text { mentioned in the } \\
\text { prescription }\end{array}$ & $\begin{array}{l}\text { Number of } \\
\text { respondents }\end{array}$ & Percentage \\
\hline Yes & 168 & 52.83 \\
No & 150 & 47.17 \\
Total & $\mathbf{3 1 8}$ & $\mathbf{1 0 0 . 0 0}$ \\
\hline
\end{tabular}

Diagnosis of disease on prescription were mentioned only to about $52 \%$ prescriptions.

Table VII : Distribution of respondents by qualification of prescribed doctor $\mathrm{n}=318$

\begin{tabular}{lccc}
\hline $\begin{array}{l}\text { Qualification of } \\
\text { prescribed Doctor }\end{array}$ & $\begin{array}{l}\text { Number } \\
\text { respondents }\end{array}$ & of & Percentage \\
\hline Qualified & 246 & 77.36 \\
Non qualified & 72 & 22.64 \\
Total & $\mathbf{3 1 8}$ & $\mathbf{1 0 0 . 0 0}$ \\
\hline
\end{tabular}

Among the available prescriptions $22.64 \%$ were by the nonqualified doctors.

\section{Discussion}

Irrational drug use and inappropriate prescribing by professionals is a world wide phenomenon. This study revealed that the number of drugs in one prescription was $3-5$ in $77 \%$ prescriptions. A study carried out in Sri Lanka in 1988 found that the average number of drugs prescribed per encounter in private getting's was 7-8. On the other hand $58 \%$ prescriptions were having $1-2$ antibiotics and no antibiotic were found in $38.99 \%$ prescriptions. However, dose of antibiotics were not mentioned to about $31 \%$ prescriptions only.

The duration 3-6 days of antibiotics was mentioned only about $23 \%$ prescriptions. Advices on life style and diagnosis were mentioned only to 32 and $52 \%$ prescriptions respectively. Study in USA revealed that $21 \%$ of all prescriptions contained at least one prescription writing error. ${ }^{11}$ Incomplete dose / directions were found in
$3 \%$ of the prescriptions. This study indicates that the dose, directions and course of drugs were the positive features in prescriptions.

In addition, the present study further pointed out that $32 \%$ of the prescriptions had the features of advices on life style. The shortcoming notes on clinical diagnosis, course of drugs and others advices on life style does not help in record linkage to the same physician or to any other physicians towards better treatment. Moreover, incomplete information hinder patients' drugs taking compliance ${ }^{19}$. A study in Denmark found $32.4 \%$ of the prescriptions did not state the diagnosis ${ }^{18}$ which is comparatively higher than the findings that were found in this study. The investigation also revealed the qualification of prescribers and found $22.64 \%$ prescriptions by non-qualified doctors.

\section{Conclusion}

The study demands a large scale investigation on the pattern of prescription in rural areas. This will help in formulating strategies to set up standard prescription guidelines in using drugs rationally. This will also help in minimizing drug resistance among patients as well as economic loss of the country.

\section{Recommendations}

1. Practitioners should be cautious about the mentioning of diagnosis properly within the prescription.

2. Practitioners should be careful in prescribing specific antibiotic with their dose and duration and attention to be paid by the practitioners in writing clear advices on life style for the patients.

\section{Acknowledgement}

It is the pleasure to acknowledge KYAMC-04 batch students namely, Kamrunnahar, Rozana Kabir Smita, Md. Nazmul Huda, Md. Rabiul Islam, Sanjida Nasreen, and Kazi Azmiri Hoque in assisting various aspects of the study, dedication and hard work in particular. Last but not least, the faculty and support staffs of the department including respondents in the study area were also contributed a lot. 


\section{References}

1. Vance MA, Millington MR; Principles of Irrational Drug Therapy. Int J. Health Serv 1986;16: 355-362.

2. WHO. Selection of Essentil Drug. Report of a WHO Expert committee.

3. Technical Report Series 641. WHO Geneva 1979.

4. WHO. 'Alam Ata Declaration', reproduced in World Health Form 1981; 2(1): 5-22.

5. Report of workshop on 'Utilization of Study Findings Related to Essential Drugs Project' Oct 1989. Sponsored by $\mathrm{MOH} \& \mathrm{FW}$ and Essential Drug Project, Bangladesh: 1-2, Annexure 20.

6. Melrose D. Bitter pills Medicine and the Third world poor. First Edition, Bangladesh: OXFAM \& UBINIG 1985; 11-26.

7. Mahler H. The Meaning of 'Health for all by the year 2000'. World Health Forum 1981; 2(1): 5 - 22.

8. DGHS. Bangladesh Health Service Report 1985. Published by Government of Bangladesh.

9. Angunawela II. Tomson GB. Drug Prescribing Patterns: A study of four institutions in Sri Lanka. Int $J$ Clin Pharmacol Ther Toxicol. 1988; 26: 69-74.

10. Abe MA; Japan's Clinic Physicians and their Behaviour. Soc Sci Med 1985; 20: 335-340.

11. Angunawela I; A Study of Prescribing in Rural Sri Lanka. Ceylon Med J 1989; 34: 125-129.

12. Christenson DB, Wertheirmer AI; Sources of Information and Infiuence on New Drugs Prescribing Among Physicians in an HMO. Soc Sci Med 1979; $13: 313-322$

13. Higginbotham N, Streiner DL; The Social Science Contribution to Pharmacoepidemiology. J Clin Epidemiol 1991; 44(Supll): 73S-82S.

14. Lexchin J; Doctors and Detailers: Therapeutic Education or Pharmaceutical Promotion? Int J Health Serv 1989;19(4) 663-679.

15. Plumridge RJ; A review of Factors Influencing Drug Prescribing (Part -I) Aust J Hosp Pharm 1983;13:16-19.

16. Plumridge RJ; A review of Factors Influencing Drug Prescribing (Part -II). Aust J Hosp Pharm 1983;13: 44-48.

17. Krupka LR, Vener AM; Prescription, Drug Advertising: Trends and Implications. Soc Sci Med 1985; 20(3): 191-197.

18. Hartley BH; Prescription Writing. B M J 1981; 282c : 711-71

19. Shaughnessy AF, Nickel RO; Prescription Writing Patterns and Errors in A Family Medicine Residency Program. J Fam Pract 1989; 29: 290 - 295. 